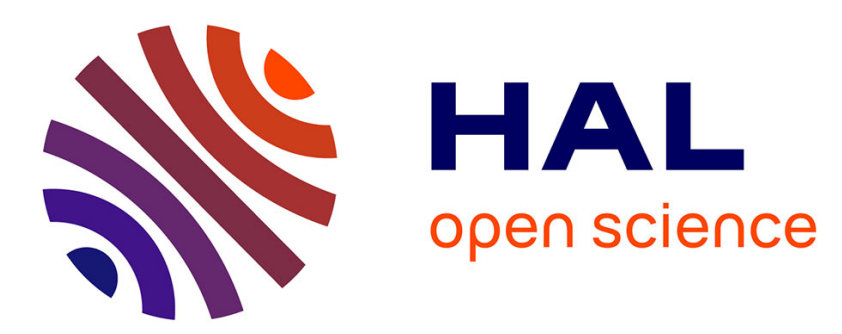

\title{
Evaluation of a procedure for positioning a crash test dummy in a railway vehicle
}

Marie-Christine Chevalier, Peter Matthews, Gaetan Hanen, Patrick Jumin, Deborah Stubbs, Bernard Roure

\section{- To cite this version:}

Marie-Christine Chevalier, Peter Matthews, Gaetan Hanen, Patrick Jumin, Deborah Stubbs, et al.. Evaluation of a procedure for positioning a crash test dummy in a railway vehicle. Journal of Rail and Rapid Transit, I MECH E Part F, 2012, 226 (4), pp. 451-454. 10.1177/0954409712438814. hal-00986002

\section{HAL Id: hal-00986002 https://hal.science/hal-00986002}

Submitted on 30 Apr 2014

HAL is a multi-disciplinary open access archive for the deposit and dissemination of scientific research documents, whether they are published or not. The documents may come from teaching and research institutions in France or abroad, or from public or private research centers.
L'archive ouverte pluridisciplinaire HAL, est destinée au dépôt et à la diffusion de documents scientifiques de niveau recherche, publiés ou non, émanant des établissements d'enseignement et de recherche français ou étrangers, des laboratoires publics ou privés. 


\section{Proceedings of the Institution of Mechanical Engineers, Part F, Journal of Rail and Rapid Transit \\ Evaluation of a procedure for positioning a crash test dummy in a railway vehicle --Manuscript Draft--}

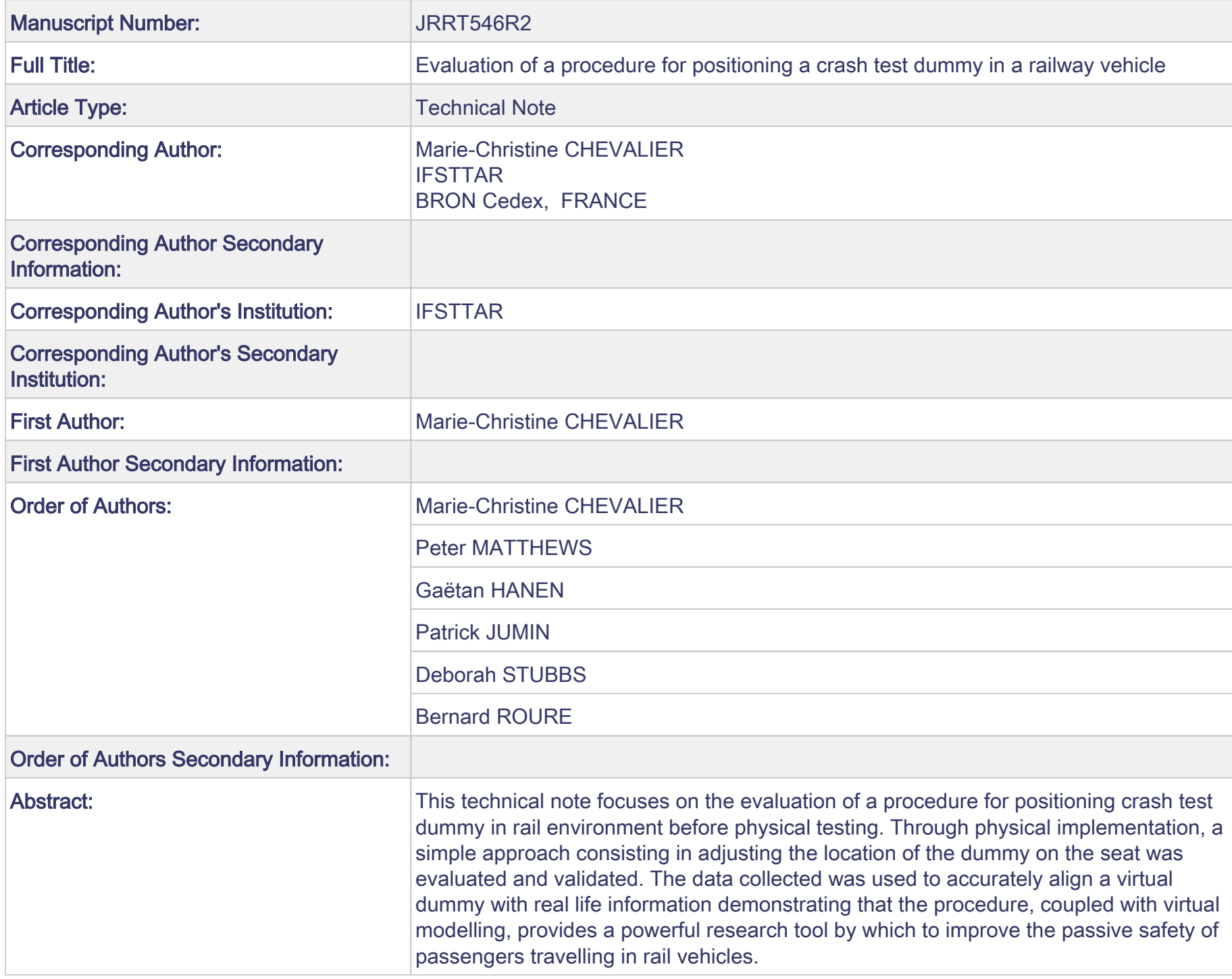




\title{
Evaluation of a procedure for positioning a crash test dummy in a railway vehicle
}

\author{
Marie-Christine Chevalier ${ }^{1}$, Peter Matthews ${ }^{2}$, Gaëtan Hanen ${ }^{1}$, Patrick Jumin ${ }^{3}$, \\ Deborah Stubbs ${ }^{4}$, Bernard Roure ${ }^{3}$ \\ ${ }^{1}$ Université de Lyon, F-69622, Lyon, France ; \\ IFSTTAR, UMR_T9406, LBMC, Bron ; Université Lyon 1, Villeurbanne. \\ ${ }^{2}$ Poised Joint Management, Independent advisor to RSSB, contact S Mills Block 2 \\ Angel Square; 1 Torren Street; London EC1V 1NY, UK \\ ${ }^{3}$ SNCF, Direction du Matériel, Centre d'Ingénierie du Matériel, 4 allée des Gémeaux, \\ 72100 LeMans, France \\ ${ }^{4}$ MIRA Ltd, Watling Street, Nuneaton, Warwickshire, CV10 0TU, UK
}

\begin{abstract}
This technical note focuses on the evaluation of a procedure for positioning crash test dummy in rail environment before physical testing. Through physical implementation, a simple approach consisting in adjusting the location of the dummy on the seat was evaluated and validated. The data collected was used to accurately align a virtual dummy with real life information demonstrating that the procedure, coupled with virtual modelling, provides a powerful research tool by which to improve the passive safety of passengers travelling in rail vehicles.
\end{abstract}

Keywords: rail, passive safety, crash test dummy, H-point, physical testing, virtual modelling

\section{BACKGROUND AND OBJECTIVES}

In case of a crash, railway occupants may be subjected to sudden displacements of large amplitude leading to violent secondary contacts with various surfaces. The resulting injury risk is usually evaluated by reproducing the event in test facility: environment of the railway passengers is reconstructed on a test sled on which appropriate crash-test dummies are seated and submitted to a deceleration corresponding to the crash scenario. The mechanical response of the dummies allows an estimation of the injury risks.

For research purposes, the dummies have to be installed in a precise, recordable, repeatable and reproducible manner. RSSB developed a protocol to physically position dummies in a seated position prior to dynamic testing [1]. The procedure was 
implemented during the European SAFEINTERIORS project - focusing on the link between interior design for railway vehicles and the passengers' safety - in order to:

- evaluate, improve and validate the protocol;

- give additional guidance regarding information to be measured and recorded;

- transfer relevant data to a virtual modelling environment and assist validation allowing in-depth study while reducing number and costs of physical testing

\section{TEST METHOD AND MATERIAL}

\subsection{Procedure}

The procedure describes how to define a reference position of the occupant on a rail seat.

At first the position of the H-point (the midpoint between the hips) for a fiftieth percentile occupant relatively to the considered seat is defined. The devoted tool, an $\mathrm{H}-$ point machine (figure 1), is installed on the seat as required in the SAE J826 automotive procedure [3]. The position of this H-point is measured in a reference frame by using physical points of the seat. This data can be used for test repeatability and transferability to the virtual environment.

The second step consists in installing the crash test dummy so that its H-point matches, within a predefined tolerance, the location obtained here above. For this, the dummy is installed with its median line corresponding to the midline of the seat. Its legs are extended horizontally and pushed so that the dummy makes contact with the seat back. In the absence of a footrest, the heels are placed on the floor; otherwise the insteps of the shoes are placed on the footrest. Afterwards, a flat rigid surface is pressed horizontally against the dummy's torso at a load of $250 \mathrm{~N}$. Then, the elbows are placed on the armrest with hands resting on the thighs whilst the feet are adjusted so that they have the same longitudinal coordinates. Finally, the knees are separated by $170 \mathrm{~mm}$, keeping the knees and ankles in the same vertical plane.

Then, the positioning of the dummy has to be validated: its H-point position is measured and compared to the value obtained in the first step. The procedure is repeated if deviation is outside a tolerance envelope of $+1-20 \mathrm{~mm}$ in the longitudinal and vertical directions. If not possible, the dummy is seated as close as possible to this envelope and its position recorded.

As a final step, all information relative to the dummy's posture and test arrangement (seat geometry, seat and table juxtaposition...) may be recorded with coordinate 
measurement equipment. Additional information may also be derived by data streaming this equipment over the required surfaces

\subsection{Physical implementation}

The procedure was implemented at Ifsttar by installing a regulatory frontal crash-test dummy (Hybrid III) in a SIRIUS Compin train seat. Measurements were taken using a FARO arm. The reference frame was the anchorage plate of the seat on the floor. The fixing bolt location of the armrest was also used, as it is easily identifiable in physical and virtual environments, and its position recorded. Each procedure (SAE J826 and positioning of the dummy with the feet on the floor) was repeated twice.

\subsection{Numerical implementation}

The seat was numerically reproduced at SNCF through a calibrated finite-element model (Altair HyperCrash® environment). A numerical model of the Hybrid III dummy was provided by Altair. Numerical implementation was carried out by adjusting the position of the seat and the posture of the dummy using the reference points and scanned envelopes recorded during physical positioning.

\section{RESULTS}

The H-point machine positioned on the seat is shown in figure 2.

Measurements with H-point manikin and Hybrid III are given in Table 1.

Table 1: Comparison of H-point position measured after SAE J826 procedure and positioning of the dummy

\begin{tabular}{|c|c|c|c|c|c|}
\hline H-Point & Procedure & $\begin{array}{c}\begin{array}{c}\text { Longitudinal }(X) \\
\mathrm{mm}\end{array} \\
\end{array}$ & $\begin{array}{c}\text { Vertical (Z) } \\
(\mathrm{mm})\end{array}$ & Mean X & Mean Z \\
\hline \multirow{2}{*}{$\begin{array}{l}\text { H-Point } \\
\text { mannikin }\end{array}$} & SAE J826 (1) & 172.7 & 469.9 & \multirow{2}{*}{173} & \multirow{2}{*}{470.1} \\
\hline & SAE J826 (2) & 173.2 & 470.2 & & \\
\hline \multirow{2}{*}{$\begin{array}{l}\text { Hybrid III } \\
\text { ATD }\end{array}$} & $\begin{array}{c}\text { After } \\
\text { Positioning (1) }\end{array}$ & 155.4 & 464 & \multirow{2}{*}{155.3} & \multirow{2}{*}{464.4} \\
\hline & $\begin{array}{c}\text { After } \\
\text { Positioning (2) }\end{array}$ & 155.1 & 464.8 & & \\
\hline & & & Difference & 17.7 & 5.6 \\
\hline
\end{tabular}


Figure 3 represents the final posture of the dummy after positioning with the feet on the floor. Positions of specific points and envelopes of the head, torso, upper and lower leg were recorded.

Positioning of the numerical dummy with reference points and scanned lines is shown in Figure 4.

\section{DISCUSSION}

The feasibility of the procedure for installing a physical dummy on a seat was validated. This was very repeatable and precise in terms of H-point position: a difference less than $1 \mathrm{~mm}$ in both longitudinal and vertical directions was found when the procedure was applied twice. The H-point position of the dummy compared to the reference value (measured with the H-point machine) was shown to be within the tolerance box $+/$ $20 \mathrm{~mm}$.

The arm positions has a great influence on the final kinematics and hence on injuries. Keeping the elbow on the armrest with the lower arm on the thigh was considered to be the most realistic position.

It was found useful to reference a set of common physical datum points on the seat in order to enable transferability between physical and virtual environments.

The data collected validates the initial positioning of the numerical dummy, improving correlation between virtual predictions and physical tests. However particular care is required on contact interfaces to avoid initial penetrations, edge intersections and numerical errors, especially between thighbones and pelvis foam. Thigh positioning could be achieved by a pre-calculation activating contact interfaces, including distortion and stress of the pelvis foam.

Limitations of this study concern the low flexibility of the dummy and access to it on the seat with coordinate measurement equipment. In trains, seats are often installed sideby-side or facing other seats or tables, complicating set-up of the dummy and associated measurements. A careful sequential assembly of the test scenario should aid the application of this procedure.

This paper focuses on the Hybrid III dummy, the positioning procedure can also be applied to the RSSB developed Hybrid III RS dummy, specifically built for testing in the rail environment [4]. 


\section{CONCLUSION}

The proposed protocol increases repeatability, reproducibility and precision of crash testing, making easier comparison of test results between test houses and going beyond physical testing to numerical simulation. It could be relevant for designers of rail transportation or be used as an input for future recommendations in railway standards relative to the interior passive safety.

\section{ACKNOWLEDGMENTS}

Our most sincere thanks go to our partners of the SAFEINTERIORS project and to the UNEX staff at Ifsttar for their valuable contribution.

\section{FUNDING}

This work was supported by the European Community in the framework of the SAFEINTERIORS project [contract No FP6-031260] with the partners UNewcastle, Alstom, ATOC, BT, CIDAUT, DB, Ifsttar, IST, MIRA, RSSB, Siemens, SNCF, UNIFE and VUKV.

\section{List of captions}

Figure 1: H-point manikin [2]

Figure 2: H-point machine after positioning

Figure 3: Hybrid III dummy after positioning with feet on the floor

Figure 4: Positioning of the numerical dummy

\section{REFERENCES}

1 Matthews P., Technical Report TEL/14317/01, Protocol for the Installation of ATD's for Crash Testing, 2003

2 Messenger A., Griffin M.J., A Guide to the Design and Comfort of Seats in Rail

Vehicles, Institute of Sound and Vibration Research, University of Southampton, 2005

3 SAE Human Accommodation and Design Devices Standards Committee, Devices

for Use in Defining and Measuring Vehicle Seating Accommodation, Standard J826, 1962, last revised 2008

4 Parent D., Tyrell D., Perlman B., Matthews P., Evaluating Abdominal Injury in Impacts with Workstation Tables, Journal of the Transportation Research Board, No. 1908, Washington D.C., 2005, pp. 205-213 


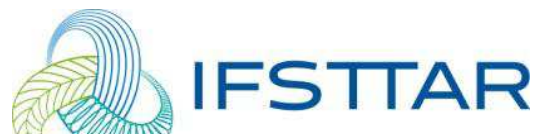

INSTITUT FRANÇAIS DES SCIENCES ET TECHNOLOGIES DES TRANSPORTS, DE L'AMÉNAGEMENT Lyon-Bron, December 21, 2011 ET DES RÉSEAUX

Manuscript number : JRRT546

\section{LBMC}

Laboratory of Biomechanics and Impact Mechanics, UMR T9406,

IFSTTAR-Univ.Lyon 1

Site IFSTTAR Lyon-Bron

25, avenue François Mitterrand

Case 24

69675 BON Cedex, France

Chevalier Marie-Christine

Research Engineer

Phone: +33 472142362

marie-christine.chevalier@ifsttar.fr
Dear Editor-in-Chief,
Dear Reviewers,

Thank you for your comments.

According to your proposal, we agree to change the title to the grammatically more correct: "Evaluation of a procedure for positioning a crash test dummy in a railway vehicle"

We hope you'll find the corrections satisfactory and be able to accept this technical note.

Looking forward to hearing from you.

Yours sincerely,

M.C. Chevalier

Marie-Christine CHEVALIER 
Figure
Click here to download high resolution image

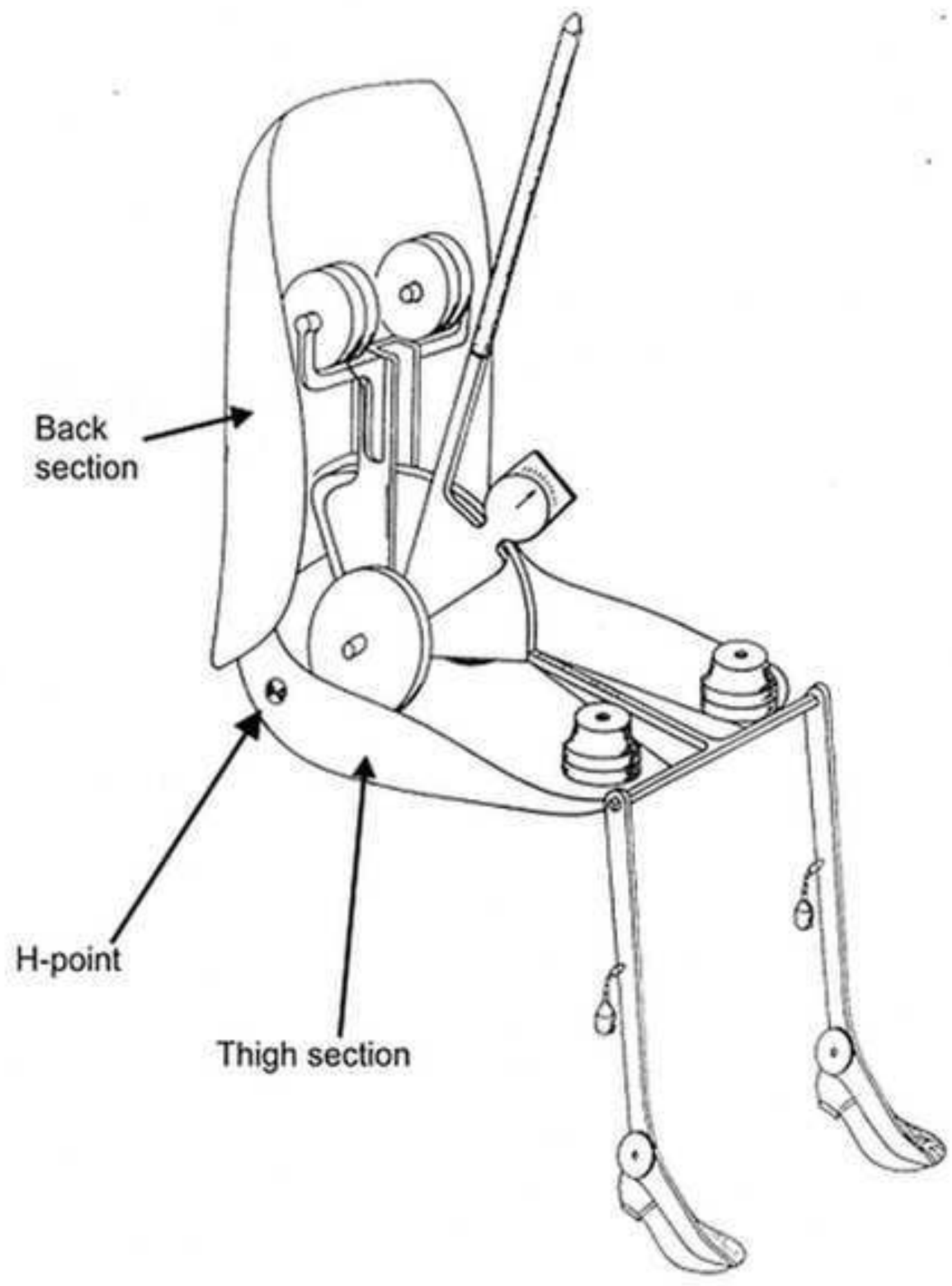


Figure

Click here to download high resolution image

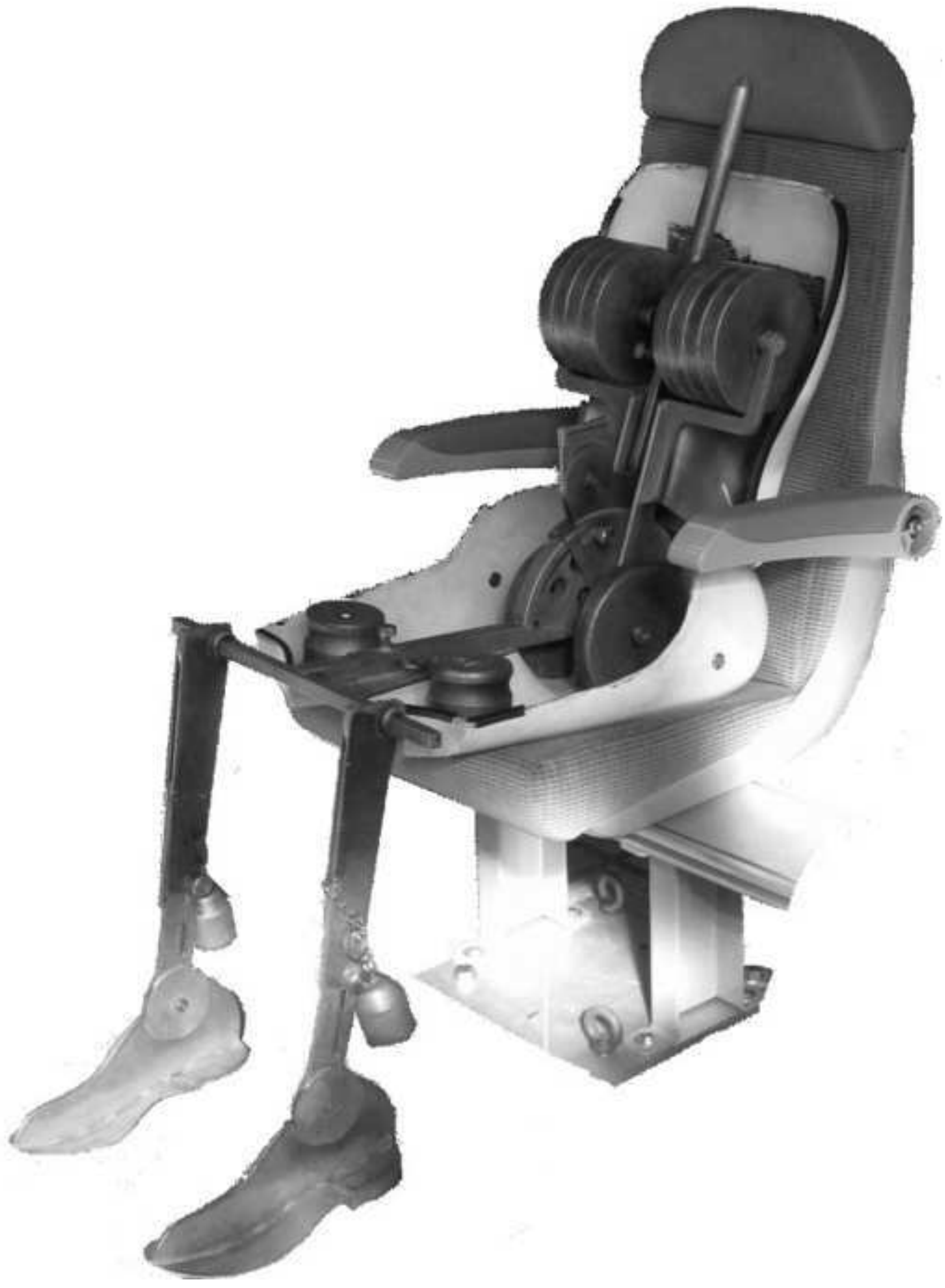


Figure

Click here to download high resolution image

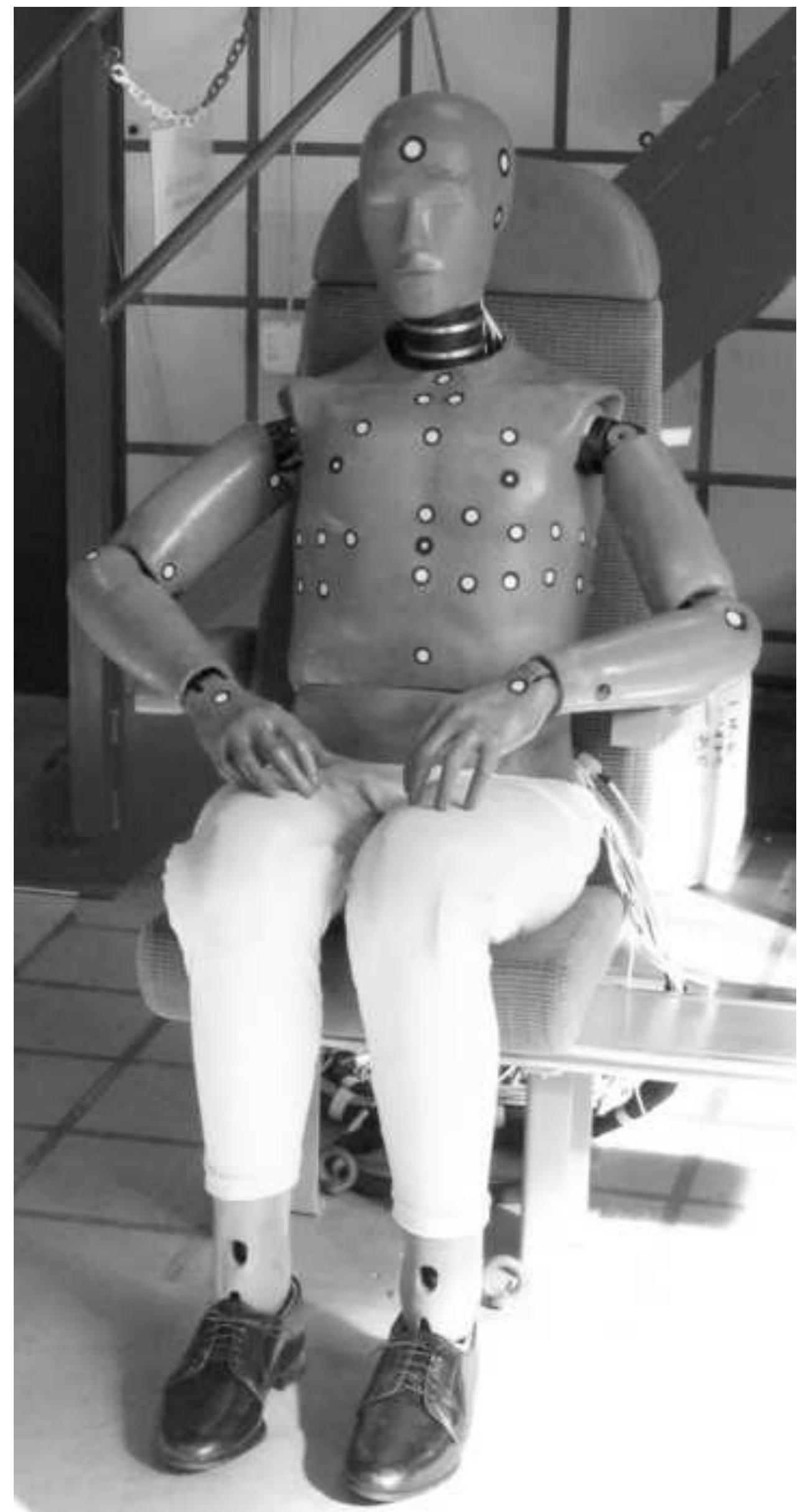


Click here to download high resolution image

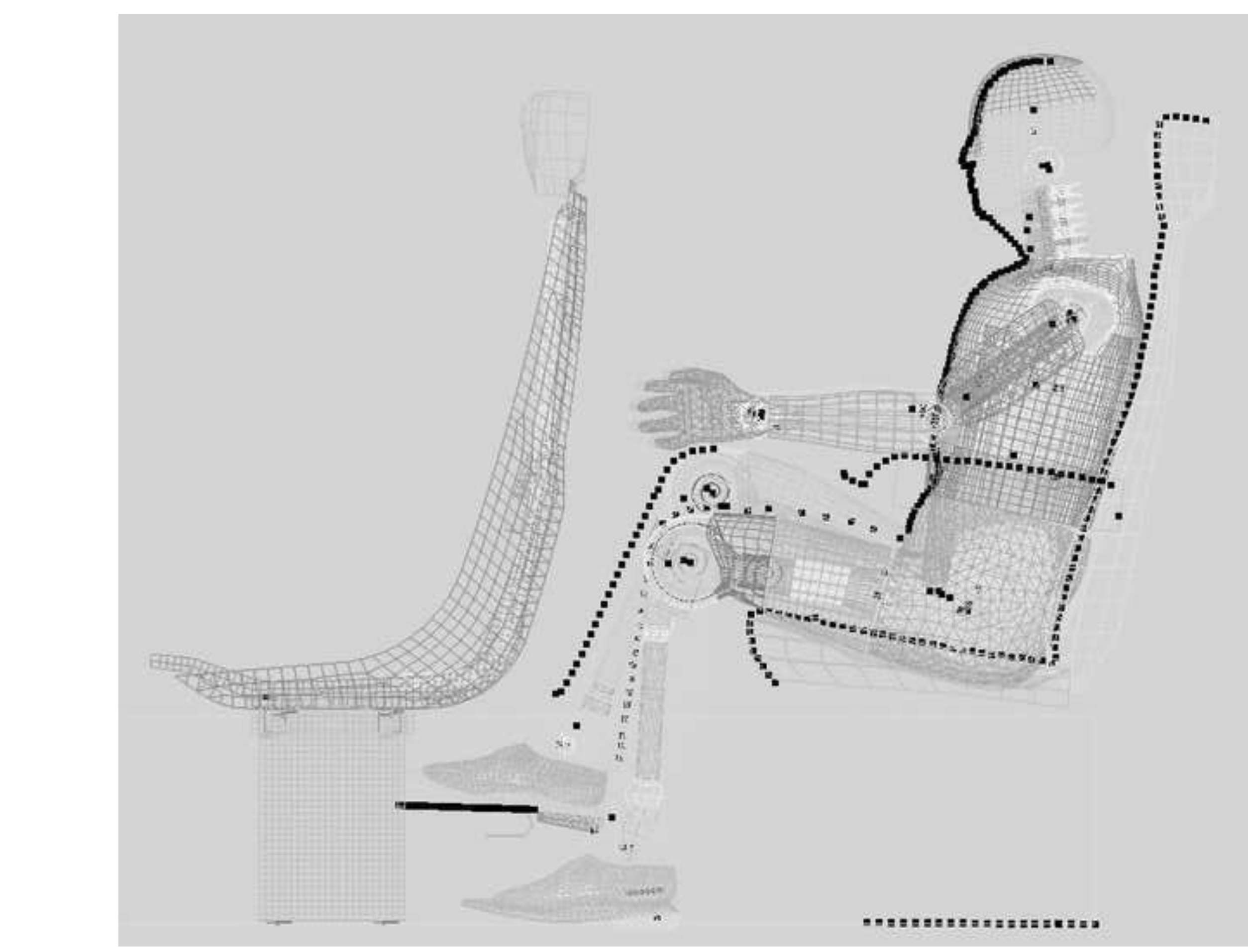

